\title{
FREQUENCY, CAUSES AND OUTCOME OF POST PARTUM HAEMORRHAGE AT LIAQAT MEMORIAL HOSPITAL KOHAT, PAKISTAN
}

\author{
Fouzia Gul ${ }^{\natural 凶}$, Musarrat Jabeen ${ }^{2}$, Heema $^{3}$
}

\section{ABSTRACT}

OBJECTIVE: To determine the frequency, causes and outcome of postpartum haemorrhage (PPH) at Liaqat Memorial Hospital (LMH) Khyber Medical University Institute of Medical Sciences (KIMS), Kohat, Pakistan.

METHODS: This descriptive study was conducted on diagnosed patients of PPH admitted in labour room of LMH, KIMS, Kohat, Pakistan. Data regarding mode of delivery, management and outcome of PPH was collected from January 2011 to December 2015. The blood loss measurement was subjective. The standard criterion for PPH definition and classification was used. The data was analysed via SPSS- 2 I.

RESULTS: Out of 46266 deliveries during the study period, documented PPH cases were 1453 (3.I4\%). The most common cause of PPH was atonic uterus $(n=566 ; 38.95 \%)$, followed by genital tract trauma $(n=489 ; 33.7 \%)$. Primary PPH was seen in I 408 (96.9\%) cases. Out of I 453 cases of PPH, 993 (68.34\%) had caesarean section, 330 (22.7I \%) were delivered vaginally and I 30 (8.95\%) had abdominal delivery for ruptured uterus. Conservative medical management was done in 535 (36.82\%) patients; repair of various kinds of tears was done in $489(33.65 \%)$ patients and subtotal abdominal hysterectomy in 198 (13.63\%) cases. Nine $(0.62 \%)$ patients had disseminated intravascular coagulation (DIC), $7(0.48 \%)$ patients had ruptured bladder along with ruptured uterus, $5(0.34 \%)$ patients had renal failure and $3(0.21 \%)$ patients developed pulmonary edema. Thirty five $(2.4 \mathrm{l} \%)$ patients died due to $\mathrm{PPH}$.

CONCLUSION: In all the observed patients of PPH, atonic uterus and genital tract trauma were the main causes while DIC and ruptured uterus were main complications of PPH.

KEY WORDS: Postpartum Haemorrhage (MeSH), Uterine Inertia (MeSH), Atonic uterus (Non-MeSH), Uterine Rupture $(\mathrm{MeSH})$, Disseminated Intravascular Coagulation (MeSH), Maternal Mortality (MeSH), Subtotal abdominal hysterectomy (Non-MeSH).

THIS ARTICLE MAY BE CITED AS: Gul F, Jabeen M, Heema. Frequency, causes and outcome of post partum haemorrhage at Liaqat Memorial Hospital Kohat, Pakistan. Khyber Med Univ J 2018;10(2):90-94.

\section{INTRODUCTION}

D ostpartum haemorrhage (PPH) is the major cause of maternal deaths in low-income countries and is responsible for about one-quarter of global maternal deaths.' $\mathrm{PPH}$ is causing 140,000 deaths each year which means one women is dying in every four minutes due to $\mathrm{PPH} .^{2}$ According to Pakistan demographic \& health survey (PDHS 2006-07), PPH is contributing for $27.2 \%$ maternal deaths in Pakistan. ${ }^{3}$

Uterine atony, retained placenta and genital lacerations are the most common causes of PPH. ${ }^{4}$ Hypovolumic shock, disseminated intravascular coagulation (DIC), hepatic dysfunction, acute respiratory distress syndrome and renal failure are the serious complications of massive $\mathrm{PPH}^{5-7}$ Among PPH survivors, an estimated $12 \%$ will suffer from the consequences of severe anemia. ${ }^{8} \mathrm{PPH}$,
$1^{凶}$ Professor, Department of Obstetrics and Gynecology, Liaqat Memorial Hospital (LMH), Khyber Medical University Institute of Medical Sciences (KIMS), Kohat, Pakistan Email:fgmeena@gmail.com

2 Professor \& Head, Department of Obstetrics and Gynecology LMH, KIMS, Kohat, Pakistan

3 Assistant Professor, Department of Obstetrics and Gynecology, LMH, KIMS, Kohat, Pakistan

Date Submitted: March 04, 2017

Date Revised: March 13,2018

Date Accepted: April 08,2018

an opportunity killer can occur unpredictably and no patient is immune from it. The rapid onset and progression of $\mathrm{PPH}$ means that high-quality services are required if we have to prevent $\mathrm{PPH}$ related mortality and morbidity.'

Although various studies have been done on causes, morbidity and mortality of PPH in Pakistan, ${ }^{5,6,10-12}$ however, the magnitude of $\mathrm{PPH} \&$ its associated complications in southern districts of Khyber Pakhtunkhwa (KP), Pakistan was not highlighted. Liaqat Memorial Hospital (LMH) Kohat is providing obstetric services to southern districts of KP and adjacent Federally Administered Tribal Areas (FATA). This study was carried out to determine the frequency, causes and outcome of PPH, over the period of last five years in $\mathrm{LMH}$, Kohat, Pakistan.

\section{METHODS}

This retrospective study was conducted on the diagnosed patient of PPH, who were admitted in Liaqat Memorial (Women \& Children) Hospital, Khyber Medical University Institute of Medical Sciences (KIMS), Kohat, Pakistan from January 20II to December 20I5. All women received with $\mathrm{PPH}$ or develop $\mathrm{PPH}$ in hospital after deliveries were included in the study. Patients on anticoagulants were excluded from study. Information was collected through a structured questionnaire with questions on bio-data, place of delivery, mode of delivery, possible causes of $\mathrm{PPH}$, medical and surgical interventions. All the data was entered in SPSS 21 and also analysed through it. 
TABLE I: MODE OF DELIVERY IN PATIENTS WITH POSTPARTUM HAEMORRHAGE

\begin{tabular}{|l|c|c|}
\hline Mode of Delivery & $\begin{array}{c}\text { Frequency } \\
(\mathbf{n = 1 4 5 3 )}\end{array}$ & \% age \\
\hline Caesarean Section & 993 & 68.34 \\
\hline Normal Vaginal Delivery & 273 & 18.79 \\
\hline Abdominal Delivery (in cases of ruptured uterus) & 130 & 8.95 \\
\hline Instrumental Delivery & 53 & 3.65 \\
\hline Assisted Breech Delivery & 04 & 0.27 \\
\hline
\end{tabular}

Out of total deliveries, documented evidence of $\mathrm{PPH}$ was found in 1453 deliveries. The measurement of blood loss was subjective and on hemodynamic instability of patient.

Ethical approval of the study was taken from ethical review board of KIMS, Kohat, Pakistan.

\section{Operational definitions:}

Primary PPH was considered as "the loss of $500 \mathrm{ml}$ or more of blood from the genital tract within 24 hours of the birth of a baby". ${ }^{13}$ Secondary PPH was defined as "abnormal or excessive bleeding from the birth canal between 24 hours and 12 weeks postnatally". ${ }^{14}$

\section{RESULTS}

Out of total 46266 deliveries from January 20II to December 2015, $40,329(87.17 \%)$ were vaginal deliveries, 5807 (12.55\%) were caesarean deliveries and $130(0.28 \%)$ patients had abdominal deliveries (in cases with ruptured uterus).

The documented cases of PPH in 46266 deliveries were 1453 (3.14\%). Out of I453 patients, 409 (28.1\%) patients were having parity of 2-4, $693(47.7 \%)$ were between para 5-8, 283 (19.5\%) were primipara and 68 (4.7\%) were of parity 9 or above.
Out of I453 patients with PPH, I3I6 (90.57\%) had in-hospital delivery while only $137(9.43 \%)$ patients were delivered at home. There were total 35 (2.41\%) maternal deaths with 18 (25.72\%) due to DIC and 8 (22.85\%) due to ruptured uterus.

The commonest mode of delivery associated with PPH was caesarean section ( $n=993 ; 68.34 \%) \quad$ [Table I]. The most common cause of PPH was atonic uterus $(n=566 ; 38.95 \%)$ followed by genital tract trauma $(n=489 ; 33.7 \%)$, and uterine rupture $(n=247 ; 17.01 \%)$ [Table II]. Secondary $\mathrm{PPH}$ was observed in 45 (3.1\%) cases.

While managing $\mathrm{PPH}$, conservative medical management was done in $\mathbf{5 3 5}$ (36.82\%) patients, repair of various types of tears was done in 489 (33.65\%) patients and subtotal abdominal hysterectomy (STAH) in 198 cases (I3.63\%) cases (Table III). Out of 198 cases of STAH, 102 (5I.5\%) were operated for rupture uterus and 96 (48.5\%) cases for atonic uterus.

Apart from these procedures, eighty (5.6\%) patients had additional conservative surgical procedures in the form of B-Lynch suture, bilateral uterine artery ligation \& bilateral internal iliac arteries ligation. Out of 247 (16.99\%) $(51.43 \%)$ due to atonic uterus, 9 cases of ruptured uterus, I 45 (58.70\%) patients had a repair and $102(41.30 \%)$ cases ended up in STAH.

Out of I453 PPH patients, 24 (I.65\%) patients developed serious complications. Nine $(0.62 \%)$ patients went into DIC, $5(0.344 \%)$ patients had renal failure, $3(0.21 \%)$ patient developed pulmonary edema and 7 $(0.48 \%)$ patients had ruptured bladder along with ruptured uterus. Patients with renal failure \& pulmonary edema were referred to intensive care units (ICU) of tertiary care hospital for further management.

\section{DISCUSSION}

In our study, PPH was reported in $3.14 \%$ of cases from January 2011 to December 20I5. Majority (90.57\%) developed PPH during hospital delivery. Primary PPH was seen in $96.9 \%$ cases. The commonest mode of delivery associated with $\mathrm{PPH}$ was $\mathrm{C} /$ Section (68.34\%) \& the most common cause of PPH was atonic uterus (38.95\%). About half of the patients with PPH had parity of $5-8$. Majority of patients $(63.18 \%)$ were managed with various surgical procedures and $36.82 \%$ had conservative medical management.

The global prevalence of PPH was estimated $10.8 \%$ and $2.8 \%$ of severe $\mathrm{PPH}$ in one systematic review. This systematic review identifying regional variations in the prevalence of $\mathrm{PPH}$ showed low prevalence of severe $\mathrm{PPH}$ in Asia (1.9\%) as compared to Africa $(5.1 \%) .^{15}$ In another multi-country survey the reported rate of PPH was I.2\%. ${ }^{16}$ The frequency of PPH in our study was $3.14 \%$ while it was $1.7 \%$ in a

TABLE II: CAUSES OF POSTPARTUM HAEMORRHAGE

\begin{tabular}{|l|c|c|}
\hline Causes of Postpartum Haemorrhage & $\begin{array}{c}\text { Frequency } \\
(\mathbf{n = 1 4 5 3 )}\end{array}$ & \%age \\
\hline Atonic Uterus & 566 & 38.95 \\
\hline Genital Tract Trauma (vaginal, cervical tears, extended caesarean section tears) & 489 & 33.66 \\
\hline Ruptured Uterus & 247 & 17.01 \\
\hline Retained Placenta & 75 & 5.16 \\
\hline Retained Conception Product & 45 & 3.09 \\
\hline Haematoma (vaginal/broad ligament) & 31 & 2.13 \\
\hline
\end{tabular}


TABLE III: MANAGEMENT OF POST PARTUM HAEMORRHAGE

\begin{tabular}{|l|c|c|}
\hline Management of Post-Partum Haemorrhage & $\begin{array}{c}\text { Frequency } \\
(\mathbf{n = 1 4 5 3 )}\end{array}$ & \%age \\
\hline Conservative Medical Management & 535 & 36.82 \\
\hline Repair of Various Types of Tears & 489 & 33.65 \\
\hline Subtotal Abdominal Hysterectomy & 198 & 13.63 \\
\hline Conservative Surgical Management & 80 & 5.5 \\
\hline Manual Removal of Retained Placenta & 75 & 5.16 \\
\hline Evacuation of Uterus & 45 & 3.1 \\
\hline Haematoma Drainage & 31 & 2.13 \\
\hline
\end{tabular}

study conducted at Liaqat National Hospital Karachi' ${ }^{2}$ \& $18.60 \%$ in a study done at Lahore. ${ }^{10}$ Systematic reviews have shown that wide variation in the global and regional prevalence of $\mathrm{PPH}$ and severe $\mathrm{PPH}$ are mainly due to methodological diversity in the measurement and prevalenceestimation of $\mathrm{PPH} .^{15,17}$

Atonic uterus has been reported as one of the major cause of PPH. The frequency of atonic uterus in our study was $38.95 \%$. It was reported $53.3 \%$ in a study at Bolan Medical College Hospital Quetta ${ }^{18} \& 28.9 \%$ in a study conducted at Jinnah Postgraduate Medical Centre Karachi. ${ }^{19}$ In developed countries, the increased incidence of PPH was shown to be associated with increase in the incidence of uterine atony. ${ }^{20}$

After uterine atony, genital tract trauma (33.65\%) was the second leading cause of PPH in our study. The frequency of genital tract trauma as causes of $\mathrm{PPH}$ was $23.3 \%$ in study at Quetta ${ }^{18}$ and $23.7 \%$ in a study done in Haryana district of India. ${ }^{21}$ Among genital tract trauma, cervical injuries represent frequent morbidities associated with vaginal deliveries. ${ }^{4}$ The frequency of instrumental delivery contributing to $\mathrm{PPH}$ in our study was $3.65 \%$, majority due to forceps delivery. Forceps and vacuum deliveries are considered as significant risk factors for maternal soft tissue injury and cervical lacerations. ${ }^{22}$ In our study, vaginal \& broad ligament haematoma were responsible for 31 $(2.13 \%)$ cases of PPH. This is in accordance with other international \& local studies. ${ }^{5,23}$

The third common cause of PPH in our study was ruptured uterus $(n=247$ : $16.99 \%)$. The frequency of ruptured uterus in other studies done in Pakistan was $20 \%{ }^{24}$ \& and I. $14 \%{ }^{25}$. The variation in frequencies is because of variation in duration \& number of patients in these studies. Out of 247 cases of ruptured uterus, 102 (4I.3\%) cases had STAH, which is in accordance with another study (45.2\%) done in Karachi. ${ }^{26}$

$\mathrm{PPH}$ is the major direct cause of maternal mortality across the globe and is responsible for one-third of all maternal deaths in Africa and Asia. ${ }^{16}$ In a WHO systematic review the leading cause of maternal death was haemorrhage signifying $27.1 \%$ (19.936.2) of maternal deaths \& PPH due to atonic uterus was identified as the main cause of haemorrhage. ${ }^{27}$ The result of our study reflect same picture as among $35(2.41 \%)$ maternal deaths, more than half $(51.43 \%)$ were due to atonic uterus, $25.72 \%$ due to DIC \& $22.85 \%$ due to ruptured uterus. Local figures for mortality rate in patients with PPH are variable and various hospital based studies have reported $0-40 \%$ mortality in patients presented with $\mathrm{PPH}$ in various hospitals in Pakistan. ${ }^{5,6,28}$ However, out of all maternal deaths, $\mathrm{PPH}$ is still the leading cause, contributing for $27.2 \%$ of maternal mortality in Pakistan. $^{3}$

International epidemiological studies have shown that obstetric haemorrhage \& hypertensive disease in pregnancy are the main reasons for intensive care admission of obstetric patients. ${ }^{29}$ In our study 24 (I.65\%) patients developed serious complications like DIC, renal failure, pulmonary edema and ruptured bladder. Patients with renal failure \& referred to tertiary care hospital for intensive care \& management. This is in accordance with a clinical review from pulmonary edema in our study were
Pakistan showing that about half of obstetric patients admitted in ICU are with haemorrhage and $61 \%$ of patients have multi-organ failure. ${ }^{30}$

\section{CONCLUSION}

In all the observed patients of $\mathrm{PPH}$, atonic uterus and genital tract trauma were the main causes while DIC and ruptured uterus were main complications of $\mathrm{PPH}$. Majority of patients were managed with various surgical procedures and about one third of patients had conservative medical management. Mortality was also observed and majority of deaths were due to atonic uterus and DIC.

\section{LIMITATIONS AND RECOMMENDATIONS}

Main limitation of our study was that it was conducted in a hospital setting and cannot represent the true figures of the population. More population-based studies are needed to determine the real burden and outcome of PPH in population. More in-depth studies are needed to explore the early identification of causes and management of PPH at primary and secondary level.

\section{REFERENCES}

I. Department of Reproductive Health and Research, World Health Organization (WHO). WHO Recommendations for the Prevention and Treatment of Postpartum Haemorrhage. Geneva: WHO; 2012. [Cited on: February 22, 2017]. Available from URL: http://apps.who.int/iris/bitstream/I 0665/754 I I/I/978924 I548502_en g.pdf?ua $=$ I

2. American College of Obstetricians and Gynecologists. ACOG Practice Bulletin: Clinical Management Guidelines for ObstetricianGynecologists Number 76, October 2006: postpartum hemorrhage. Obstet Gynecol 2006 Oct; 108(4): 1039-47.

3. PDHS, National Institute of Population Studies \& Demographic 
and Health Surveys. Pakistan Demographic and Health Survey. 2006-2007. [Cited on: February 22, 2017]. Available from URL: http://www.nips.org.pk/PDHS__2006-07.htm.

4. Landy HJ, Laughon SK, Bailit JL, Kominiarek MA, GonzalezQuintero VH, Ramirez M, et al. Characteristics associated with severe perineal and cervical lacerations during vaginal delivery. Obstet Gynecol 20II; I 17:627-35. DOI: 10.1097/AOG.0b013e3 I820afaf2.

5. Sheikh L, Najmi N, Khalid U, Saleem $\mathrm{T}$. Evaluation of compliance and outcomes of a management protocol for massive postpartum hemorrhage at a tertiary care hospital in Pakistan. BMC Pregnancy Childbirth 20II;II(I):28. DOI: I0. I |86/|47|-2393-I I-28.

6. Bibi S, Danish N, Fawad A, Jamil M. An audit of primary post partum haemorrhage. J Ayub Med Coll Abbottabad 2007; 19(4): 102-6.

7. Hoveyda F, MacKenzie IZ. Secondary postpartum haemorrhage: incidence, morbidity and current management. $\mathrm{Br}$ J Obstet Gynaecol 200 I; I08(9):927-30.

8. AbouZahr C. Global burden of maternal death and disability. $\mathrm{Br}$ Med Bull 2003;67: I - I I.

9. Weeks A. The prevention and treatment of postpartum haemorrhage: what do we know, and where do we go to next? $\mathrm{Br}$ J Obstet Gynecol 2015 Jan; I 22 ( 2 ): 202 - I 0 . DO I: |0.| | | |/|47|-0528. | 3098.

10. Munir SI, Sadiq A, Ishtiaq S. Frequency of causes of primary postpartum haemorrhage in a tertiary care hospital. Ann King Edward Med Uni 2015;2I (I):27-32 . DOI: 10.21649/akemu.v2Iil.692

II. Gani N, Ali TS. Prevalence and factors associated with maternal postpartum haemorrhage in Khyber Agency, Pakistan. J Ayub Med Coll
Abbottabad 20I 3;25(I-2):8I-5.

12. Edhi MM, Aslam HM, Naqvi Z, Hashmi H. Postpartum hemorrhage: causes and management. BMC Res Notes 2013 Jun 18;6:236. DOI: 10.1 I86/1756-0500-6-236.

13. Mousa HA, Blum J, Abou El Senoun G, Shakur H, Alfirevic Z. Treatment for primary postpartum haemorrhage. Cochrane Database Syst Rev 20I4;(2):CD003249. DOI: 10.1002//465 I858.CD003249.pub3.

14. Alexander J, Thomas P, Sanghera J. Treatments for secondary postpartum haemorrhage. Cochrane Database Syst Rev 2002; (I):CD002867. DOI: I0.1002/I465 I858.CD002867.

15. Calvert C, Thomas SL, Ronsmans C, Wagner KS, Adler AJ, Filippi V. Identifying Regional Variation in the Prevalence of Postpartum Haemorrhage: A Systematic Review and Meta-Analysis. PLoS One 20I2;7(7):e4III4. DOI: 10.137I/ journal.pone.004 III4.

16. Sheldon WR, Blum J, Vogel JP, Souza JP, Gülmezoglu AM, Winikoff $B$, et al. Postpartum haemorrhage management, risks, and maternal outcomes: findings from the World Health Organization Multicountry Survey on Maternal and Newborn Health. Br J Obstet Gynecol 2014 Mar;(I2I Suppl I):5-I3. DOI: I0.1 III/|47|-0528.12636.

17. Carroli G, Cuesta C, Abalos E, Gulmezoglu AM. Epidemiology of postpartum haemorrhage: a systematic review. Best Pract Res Clin Obstet Gynaecol 2008 Dec;22(6):999-I0I2. DOI: 10.1016/j.bpobgyn.2008.08.004.

18. Humza S, Saeed S, Ali H, Parkani GM, Kasi Z. Various presentations and management of primary postpartum haemorrhage at $\mathrm{BMCH}$, Quetta, Pakistan. Rawal Med J 2017;42(I):68-72.

19. Korejo R, Nasir A, Yasmin H, Bhutta S. Emergency obstetric hysterectomy. J Pak Med Assoc 2012 Dec;62(I2): I 322-5.

20. Callaghan WM, Kuklina EV, Berg CJ. Trends in postpartum hemorrhage: United States, 1994-2006. Am J Obstet Gynecol 2010;202(4): 353.el-6. DOI: 10.1016/j.ajog. 2010.01 .011 .

21. Duhan L, Nanda S, Sirohiwal D, Dahiya P, Singhal S, Vandana. A retrospective study of maternal and perinatal outcome in patients of postpartum haemorrhage in a tertiary care hospital. Int J Reprod Contracept Obstet Gynecol 2016 Jun;5(6): I897-90I DOI: 10.18203/ 2320- I770.ijrcog20 I6I686.

22. Kabiru WN, Jamieson D, Graves W, Lindsay $M$. Trends in operative vaginal delivery rates and associated maternal complication rates in an inner-city hospital. Am J Obstet Gynecol 200 I; 184(6): I I I 2-4. DOI: 10.1067/mob.2001.115178.

23. Caughey $A B$, Sandberg PL, Zlatnik MG, Thiet MP, Parer JT, Laros RK Jr. Forceps compared with vacuum: rates of neonatal and maternal morbidity. Obstet Gynecol 2005; 106 (5 Pt I):908-12. DOI: 10.1097/0I. AOG.0000182616.39503.b2.

24. Khooharo Y, Yousfani JZ, Malik SH, Amber A, Majeed N, Malik NH, et al. Incidence and management of rupture uterus in obstructed labour. J Ayub Med Coll Abbottabad 2013 Jan-Jun;25(I-2): |49-5I.

25. Alam I, Khan A, Ahmed R, Begum N. A two Year Review of Uterine Rupture at Gynaecology Unit-A Ayub Teaching Hospital. J Ayub Med Coll Abottabad 2000; I 2(2):2 I -2.

26. Aziz S. Indication of Emergency Hysterectomy in Pakistani Patients. J Soc Obstet Gynaecol Pak 2017;7(I):45-9.

27. Say L, Chou D, Gemmill A, Tunçalp Ö, Moller AB, Daniels J, et al. Global causes of maternal death: A WHO systematic analysis. Lancet Glob Health 20I4;2(6):e32333. DOI: 
10.1016/S2214-109X(14)70227-X.

28. Naz H, Sarwar I, Fawad A, Nisa AU. Maternal morbidity and mortality due to primary $\mathrm{PPH}-$-experience at Ayub Teaching Hospital Abbottabad. J Ayub Med Coll Abbottabad 2008 Apr-Jun;20(2):59-65.
29. Wanderer JP, Leffert LR, Mhyre JM, Kuklina EV, Callaghan WM, Bateman BT. Epidemiology of obstetricrelated ICU admissions in Maryland: 1999-2008. Crit Care Med J 20I3;4I(8): I 844-52. DOI: I0.1097/CCM.0b0I3e31828a3e24.
30. Qureshi R, Irfan Ahmed S, Raza A, Khurshid A, Chishti U. Obstetric patients in intensive care unit: Perspective from a teaching hospital in Pakistan. J Royal Soc Med Open 20I6;7 ( I I ): I - 8. DO I: $10.1177 / 2054270416663569$.

\section{AUTHOR'S CONTRIBUTION}

Following authors have made substantial contributions to the manuscript as under:

FG: Concept \& study design, acquisition, analysis \& interpretation of data, drafting the manuscript, final approval of the version to be published

MJ: Acquisition of data, drafting the manuscript, critical revision, final approval of the version to be published

He: Acquisition of data, final approval of the version to be published

Authors agree to be accountable for all aspects of the work in ensuring that questions related to the accuracy or integrity of any part of the work are appropriately investigated and resolved. 